\title{
Application of the Socio-Economic Impact Classification for Alien Taxa (SEICAT) to a global assessment of alien bird impacts
}

\author{
Thomas Evans ${ }^{1,2,3}$, Tim M. Blackburn ${ }^{4,5}$, Jonathan M. Jeschke ${ }^{1,2,3}$, \\ Anna F. Probert ${ }^{6}$, Sven Bacher ${ }^{6}$
}

I Institute of Biology, Freie Universität Berlin, Königin-Luise-Str. 1-3, 14195, Berlin, Germany 2 LeibnizInstitute of Freshwater Ecology and Inland Fisheries (IGB), Müggelseedamm 310, 12587, Berlin, Germany 3 Berlin-Brandenburg Institute of Advanced Biodiversity Research (BBIB), Königin-Luise-Str. 2-4, 14195, Berlin, Germany 4 Centre for Biodiversity and Environment Research, Department of Genetics, Evolution and Environment, University College London, Gower Street, London, WC1E 6BT, UK 5 Institute of Zoology, Zoological Society of London, Regent's Park, London, NW1 4RY, UK 6 Department of Biology, Unit Ecology \& Evolution, University of Fribourg, Chemin du Musée 10, 1700, Fribourg, Switzerland

Corresponding author: Thomas Evans (thomas.evans@fu-berlin.de)

Academic editor: C. C. Daehler | Received 15 February 2020 | Accepted 23 June 2020 | Published 15 October 2020

Citation: Evans T, Blackburn TM, Jeschke JM, Probert AF, Bacher S (2020) Application of the Socio-Economic Impact Classification for Alien Taxa (SEICAT) to a global assessment of alien bird impacts. In: Wilson JR, Bacher S, Daehler CC, Groom QJ, Kumschick S, Lockwood JL, Robinson TB, Zengeya TA, Richardson DM (Eds) Frameworks used in Invasion Science. NeoBiota 62: 123-142. https://doi.org/10.3897/neobiota.62.51150

\begin{abstract}
We use a recently proposed framework, the Socio-Economic Impact Classification for Alien Taxa (SEICAT) to undertake the first global assessment of the impacts of alien birds on human well-being. A review of the published literature and online resources was undertaken to collate information on the reported socio-economic impacts of 415 bird species with self-sustaining alien populations worldwide. These data were then categorised following the SEICAT guidelines. Impact data were found for 57 (14\%) of the 415 alien bird species in this study. All but two of these species were found to have minor impacts on human well-being. The most significant threat to human well-being posed by alien birds may be associated with their impacts on aviation safety. About two-thirds of the impact data found described agricultural impacts. No data were found describing disease transmission impacts on humans. We lack data for developing regions of the world: this is of concern as alien species can threaten livelihoods in developing countries, particularly by affecting agricultural production and hence food security. Most assessments were allocated
\end{abstract}

Copyright Thomas Evans et al. This is an open access article distributed under the terms of the Creative Commons Attribution License (CC BY 4.0), which permits unrestricted use, distribution, and reproduction in any medium, provided the original author and source are credited. 
a 'Low' confidence score. This may be because SEICAT is a new framework, requiring data on the way in which alien species affect human well-being, as measured by changes to human activities: even where we do have data describing an alien bird impact, information on how profoundly this impact affects people's activities is currently rarely available.

\section{Keywords}

Aviation safety, biological invasions, common starling, Canada goose, Eurasian blackbird, frugivory, grape damage, human well-being

\section{Introduction}

The socio-economic impacts of alien species can be severe, affecting human health and livelihoods across the globe. For example, in the Mediterranean, the silver-cheeked toad-fish (Lagocephalus sceleratus) impacts commercial and recreational fishing activities by predating upon fish caught in nets and damaging fishing gear. It is also highly toxic and has little economic value, but represents $4 \%$ of the total weight of artisanal catches, resulting in reduced incomes (Coro et al. 2018). In 2005, the tiger mosquito (Aedes albopictus) caused an outbreak of chikungunya fever on Reunion Island, which resulted in approximately 255,000 infections and more than 200 deaths (Josseran et al. 2006). The cumulative (present-value) costs of the golden apple snail (Pomacea canaliculata) invasion to rice agriculture in the Philippines in 1990 were between US $\$ 425$ million - 1.2 billion/year ( $€ 380$ million - 1.1 billion/year) (Naylor 1996).

While there are many examples of alien species having socio-economic impacts, systematic assessments of these impacts for a given alien higher taxon are rare. Here, we address this with an analysis of the socio-economic impacts of an entire alien taxon, birds, the alien populations of which are relatively well documented (Dyer et al. 2017a). Alien birds can impose a substantial financial burden: in just six countries (the UK, USA, Australia, South Africa, India and Brazil), they have been estimated to cause combined economic losses of US\$2.4 billion/year ( $€ 2.2$ billion/year) (Pimentel et al. 2001). In Australia, the Eurasian blackbird (Turdus merula) and common starling (Sturnus vulgaris) cause significant damage to vineyards and orchards (Tracey and Saunders 2003): should the common starling establish in Western Australia, the estimated cost to the region resulting from agricultural damage would be AU\$ 43.7 million/year (€ 26.2 million/year) (Campbell et al. 2016). In the UK, Canada geese (Branta canadensis) are a significant threat to aviation safety: in 1998, a Boeing 767 struck a flock of Canada geese on landing at Heathrow Airport in London, causing extensive damage to the plane (Civil Aviation Authority, no date). In Florida, monk parakeets (Myiopsitta monachus) build nests on electrical utility facilities, including distribution poles, transmission line towers and electrical substations. The nests cause regular power outages, pose a health and safety concern and result in lost revenue for utility companies (Avery et al. 2002). On Haiti, the village weaver (Ploceus cucullatus) is a significant pest to rice agriculture (Fitzwater 1973). Given the wide-ranging socio- 
economic impacts of alien birds, an analysis that categorises, scores and compares species based on the mechanism and severity of their impacts (as has been done for the environmental impacts of alien birds (Evans et al. 2016) using a related framework, the Environmental Impact Classification for Alien Taxa (EICAT: Blackburn et al. 2014)), would provide useful insights regarding the most damaging species. It would also enable the identification of regions sustaining the most severe impacts, potentially informing management interventions to protect human health and livelihoods.

To date, four studies have used scoring systems to quantify the socio-economic impacts of alien birds (Shirley and Kark 2009; Kumschick and Nentwig 2010; Kumschick et al. 2013; Evans et al. 2014). Shirley and Kark (2009) scored alien bird impacts under two broad categories: economic impacts resulting from damage to agricultural crops and human health impacts resulting from disease transmission, noise disturbance and threats to aviation safety. They found alien birds from three families (true parrots (Psittacidae), pheasants (Phasianidae) and ducks, geese and swans (Anatidae)) to have the most severe economic impacts and pigeons and doves (Columbidae) and true parrots to have the most severe human health impacts. The other three studies used the Generic Impact Scoring System (GISS: Nentwig et al. 2010) to quantify the severity of alien bird impacts using six categories: agriculture, animal production, forestry, human infrastructure, human health and human social life. Kumschick and Nentwig (2010) found four alien bird species to have the most severe economic impacts in Europe: the Canada goose, rose-ringed parakeet (Psittacula krameri), monk parakeet and the African sacred ibis (Threskiornis aethiopicus). Kumschick et al. (2013) found that most alien birds generally have relatively minor economic impacts in Europe, with the exception of the Canada goose. Evans et al. (2014) found the economic impacts of alien birds in Australia to be more frequently documented than their environmental impacts, that there are more species with recorded economic impacts in Australia than in Europe (14 vs. 7) and that these impacts tend to be more severe in Australia than in Europe. The species with the most severe economic impacts in Australia included the common starling, common myna (Acridotheres tristis) and house sparrow (Passer domesticus). These regional studies have provided useful insights regarding the types of alien birds that have the most severe impacts on a range of socio-economic activities in Europe and Australia. However, these studies did not adopt a common metric with which to determine the severity of socio-economic impacts generated by alien birds: this means they are less useful when trying to directly compare the severity of impacts caused by different alien bird species and sustained across different regions of the world.

The recently proposed Socio-Economic Impact Classification for Alien Taxa (SEICAT: Bacher et al. 2018) has been developed to provide a standardised method to quantify and categorise the broad range of socio-economic impacts generated by alien species. Crucially, it differs from previous scoring systems (e.g. D’hondt et al. 2014; Nentwig et al. 2016), because it uses changes in human activities that result from the impacts of an alien species as a common metric for assessing the severity of these impacts. In so doing, SEICAT enables direct comparisons to be made across alien taxa and regions regarding the severity of the impacts caused by alien species. Here, we 
apply SEICAT to undertake the first global assessment of the impacts of alien birds on human well-being. Based on the results of previous studies, we expect to find variation in the severity of these impacts across alien bird orders and geographic regions, with impacts in Europe being generally minor. We also expect to find a lack of data describing the socio-economic impacts of many alien bird species. By undertaking this assessment, we aim to further our understanding of the global threat posed by alien birds to human well-being and to identify knowledge gaps, directing future alien bird impact studies. When combined with the recently produced global dataset on the environmental impacts of alien birds (Evans et al. 2016), the data generated by this study will form the first complete, global dataset on the impacts of alien species from an entire taxonomic class.

\section{Methods}

\section{Data}

A list of 415 alien bird species with self-sustaining populations worldwide (i.e. established breeding populations that can persist without further human intervention) was taken from Evans et al. (2016). A review to identify literature on the socio-economic impacts of these species was undertaken following the approach adopted in Evans et al. (2016) as summarised in the Suppl. material 1: Appendix A. Using the information gathered during the literature review, each alien bird species was allocated to one of five SEICAT impact categories, depending on its most severe impacts to human wellbeing. In order of severity, these categories are: Minimal Concern (MC), Minor (MN), Moderate (MO), Major (MR) and Massive (MV).

The impact categories have been designed to reflect an increase in the order of magnitude of a particular impact caused by an alien species to human well-being. Impacts of $\mathbf{M C}$ do not affect human well-being; $\mathbf{M N}$ impacts make it difficult for people to participate in their normal activities and individuals suffer in at least one constituent of human well-being (e.g. security, material assets, health); MO impacts result in a reduction in the size of an activity, with fewer people participating in it (e.g. the partial abandonment of an activity); MR impacts result in the local disappearance of an activity from all or part of an area invaded by an alien taxon (e.g. people switch to other activities), but this impact is considered to be reversible within a decade if the alien species is controlled or removed; MV impacts result in the local disappearance of an activity and this change is likely to persist for at least a decade, even if the alien species is controlled or removed.

A series of impact descriptions were used to guide the assessment process, as shown in the Suppl. material 3: Table S1. As an example, on Easter Island, the chimango caracara (Phalcoboenus chimango) feeds on insects on the backs of cattle and horses. This feeding can damage the skin of the livestock, which reduces the value of the hides, and results in lost income for livestock owners (Johnson et al. 1970). However, there is no 
evidence to show that this impact has resulted in a reduction in the number of people buying and selling cattle and horses on Easter Island. As such, recorded impacts for the chimango caracara match the impact description relating to $\mathbf{M N}$ under the SEICAT guidelines (Bacher et al. (2018): see Suppl. material 3: Table S1). The scoring of impacts was undertaken by one assessor (T.E.), and it is therefore possible that the results of the assessment were influenced by subjectivity. However, the impact descriptions used to guide the assessment process (Suppl. material 3: Table S1) have been developed in order to minimise subjectivity. The impact descriptions are analogous to those used for the IUCN EICAT protocol, which has been used by individual assessors to undertake global assessments of the environmental impacts of alien species (e.g. Canavan et al. 2019).

SEICAT does not include formal alien species impact mechanisms with which to categorise the type of impacts caused by alien species: this is because any such mechanisms are likely to vary depending on the impacting alien species and the people/communities affected. For this assessment, and based on the findings of previous studies (Shirley and Kark 2009; Kumschick and Nentwig 2010; Kumschick et al. 2013; Evans et al. 2014), we identified six broad mechanisms through which alien birds may affect human well-being: damage to agriculture (for example, by grazing and trampling on growing crops or by spoiling harvested crops with droppings); damage to public facilities, buildings and utilities (for example, by spoiling public spaces and recreational areas with droppings, damaging ornamental trees in public parks though herbivory, and by nesting on buildings and pylons, which blocks gutters and causes power outages); being a public nuisance (by being noisy, aggressive and spreading rubbish); posing a risk to aviation safety (through collisions with aircraft); transmitting diseases to animals; and transmitting diseases to humans. To reflect any uncertainty over the accuracy of the assessments, including the correct classification of an alien bird species using the SEICAT impact categories, a confidence score of 'High', 'Medium' or 'Low' was allocated to each assessment using the EICAT guidelines (IUCN 2020) which are also applicable to SEICAT assessments. For example, the data describing the impacts caused by the Eurasian blackbird on the grape growing industry in Tasmania were published and peer-reviewed, but the report expressed some uncertainty over whether these impacts caused a reduction to the scale of grape growing operations on Tasmania (Guiler 1989). Consequently, a confidence score of 'Medium' was allocated to the SEICAT assessment for this species (see Probert et al. (2020) for a broader discussion on the classification of uncertainties in EICAT and SEICAT). Where insufficient data was available to assess the socio-economic impacts of an alien species, it was categorised as Data Deficient (DD).

\section{Analysis}

Contingency table tests (unconditional exact tests: the FunChisq package (Zhong and Song 2019)) were used to analyse the actual and expected distribution of: (i) the severity of impacts across alien bird orders and geographic regions; (ii) alien bird species that 
have and do not have reported socio-economic impacts, that also have and do not have reported environmental impacts; and (iii) impact data availability across regional alien bird species richness scores.

Regional alien bird species richness scores (the number of alien bird species with established populations in a region) were calculated using the Global Avian Invasions Atlas (GAVIA: Dyer et al. 2017a). Analysis of regions was undertaken at the continental scale using the following groups: Africa, Asia, Australasia, Europe, North and Central America, South America and Oceanic Islands. Following Evans et al. (2016), due to the relatively small size of our impact dataset, impact severity data were converted into a two-level response variable: 'less severe impacts' being those categorised as $\mathbf{M C}$ or $\mathbf{M N}$ under SEICAT, and 'more severe impacts' being those categorised as MO, MR or MV (these three impact categories are analogous to the 'harmful' categories as described in the IUCN EICAT guidelines (IUCN 2020)). We excluded the rock dove (Columba livia) from our study, as there is some uncertainty as to the extent of its native and alien range. All analyses were carried out in $\mathrm{R}$ version 3.5.3 (R Core Team 2019).

\section{Results}

We found 128 impact reports for 57 (14\%) of the 415 bird species with self-sustaining alien populations worldwide (see Suppl. material 2: Appendix B for a summary). These 57 species are from six orders of alien birds (Figure 1): Passeriformes (perching birds: 25 species, $44 \%$ of all species with impact data), Psittaciformes (parrots: 13, 23\%), Galliformes (gamebirds: 9, 16\%), Anseriformes (waterfowl: 5, 9\%), Columbiformes (pigeons and doves: 4, 7\%) and Falconiformes (falcons and caracaras: 1, 2\%). No impact data were found for 358 species, which were categorised as Data Deficient (DD) under SEICAT. Furthermore, no impact data were found for 20 of the 26 orders of birds containing species with self-sustaining alien populations worldwide: these 20 orders are therefore entirely DD. Impact data availability is randomly distributed across the six orders for which impact data were available (unconditional exact test: chi-square value $=1.071$, degrees of freedom $=4, P=0.841$, estimate $=0.054)($ Suppl. material 1: Table S2). There are more alien bird species with reported socio-economic impacts that also have reported environmental impacts than would be expected by chance (unconditional exact test: chi-square value $=38.7$, degrees of freedom $=1, P<0.001$, estimate $=0.305)($ Table 1$)$.

Several alien bird species were found to have equally severe impacts through more than one impact mechanism: for example, the Canada goose consumes crops, fouls public parks and poses a risk to aviation safety. The majority (98\%) of the impacts reported were classified as being 'less severe' $(\mathbf{M C}$ impacts $=9 ; \mathbf{M N}$ impacts $=117)$, with the remainder being classified as 'more severe' (MO impacts $=2$; $\mathbf{M R}$ and $\mathbf{M V}$ impacts $=0$ ) (Figure 2). Impact magnitudes are randomly distributed across orders (unconditional exact test: chi-square value $=0.214$, degrees of freedom $=4, P=0.958$, estimate $=0.041)($ Suppl. material 3: Table S3).

Impacts on agriculture was the most frequently reported impact mechanism (83 impact reports, $65 \%$ of all reported impacts), followed by damage to public facilities, 


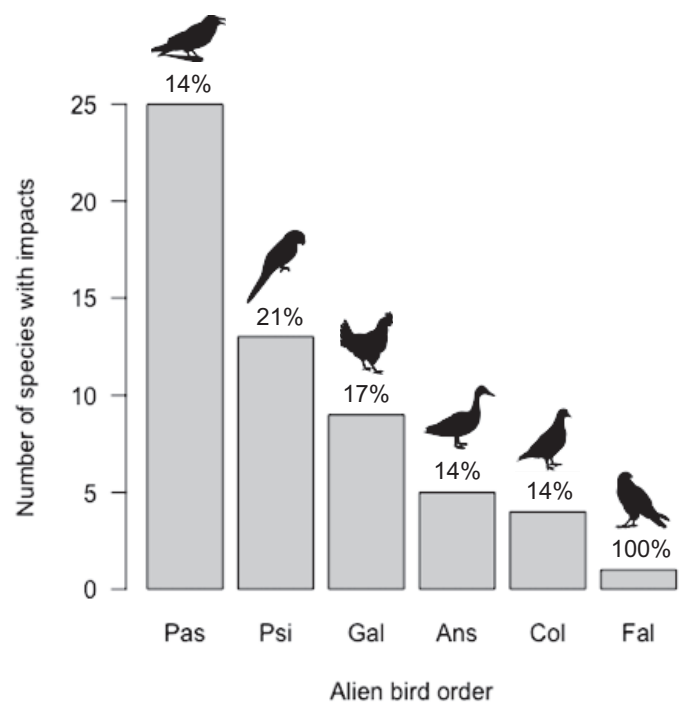

Figure I. The number of alien bird species with recorded socio-economic impacts from each of six orders. Pas: Passeriformes; Psi: Psittaciformes; Gal: Galliformes; Ans: Anseriformes; Col: Columbiformes; Fal: Falconiformes. Total species with impacts $=57$. A further 358 species were categorised as being Data Deficient (DD) under SEICAT. \% = proportion of bird species in each order with impact data.

Table I. Contingency table (unconditional exact test) showing actual and expected numbers of alien bird species that have or do not have reported socio-economic impacts that also have or do not have reported environmental impacts. Expected values are displayed in italics.

\begin{tabular}{lccc}
\hline & $\begin{array}{c}\text { Alien bird species with reported } \\
\text { environmental impacts }\end{array}$ & $\begin{array}{c}\text { Alien bird species without reported } \\
\text { environmental impacts (DD species) }\end{array}$ & Total \\
\hline Alien bird species with reported socio- & 45 & 12 & 57 \\
economic impacts & 16.34 & 40.66 & 358 \\
Alien bird species without reported socio- & 74 & 284 & 415 \\
economic impacts (DD species) & 102.66 & 255.35 & $\mathbf{2 9 6}$ \\
Total & $\mathbf{1 1 9}$ & & \\
\hline
\end{tabular}

Chi-square value $=38.7$, degrees of freedom $=1, P<0.001$, estimate $=0.31$.

buildings and utilities (26 impacts, 20\%) (Figure 2). One report described disease transmission impacts on animals; no reports were found describing disease transmission impacts on humans. Impact magnitudes are randomly distributed across impact mechanisms (unconditional exact test: chi-square value $=0.922$, degrees of freedom $=$ 3, $P=0.66$, estimate $=0.085)$ (Suppl. material 3: Table S4). Impact mechanisms are non-randomly distributed across alien bird orders (unconditional exact test: chi-square value $=31.7$, degrees of freedom $=12, P=0.003$; estimate $=0.29$ ): there are fewer parrot species with impacts on agriculture than would be expected by chance, and more parrot and waterfowl species and fewer perching bird species with impacts on public facilities, buildings and utilities than would be expected by chance (Table 2). 
(A)

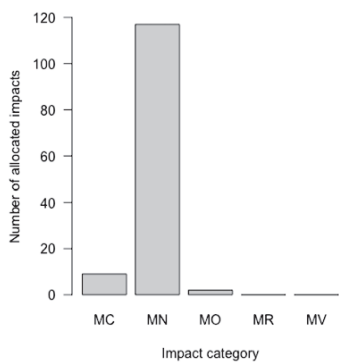

(B)

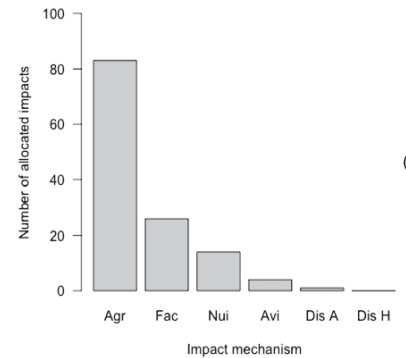

(C)

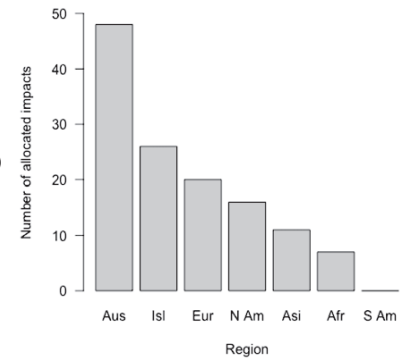

Figure 2. The severity and type of socio-economic impacts caused by alien birds, and the regions in which they are sustained. This figure shows the number of impact records for each of: (A) five impact categories; (B) six impact mechanisms; and (C) seven regions of the world. MC: Minimal Concern; MN: Minor; MO: Moderate; MR: Major; MV: Massive. Agr: Damage to agriculture; Fac: Damage to public facilities, buildings and utilities; Nui: public nuisance; Avi: risk to aviation safety; Dis A: transmission of diseases to animals; Dis H: transmission of diseases to humans. Aus: Australasia; Isl: Oceanic Islands; Eur: Europe; N Am: North (and Central) America; Asi: Asia; Afr: Africa; S Am: South America. Total impact reports = 128 .

Table 2. Contingency table (unconditional exact test) showing actual and expected numbers of impact allocations to each impact mechanism for each order of alien birds. Expected values are displayed in italics. Data for impacts by Falconiformes and disease transmission were removed from the dataset for the test, due to low sample sizes (one $\mathbf{M N}$ impact each).

\begin{tabular}{|c|c|c|c|c|c|}
\hline & Damage to agriculture & $\begin{array}{l}\text { Damage to public facilities, } \\
\text { buildings and utilities }\end{array}$ & Nuisance & Aviation safety & Total \\
\hline \multirow[t]{2}{*}{ Passeriformes } & 38 & 3 & 5 & 1 & 47 \\
\hline & 30.59 & 9.7 & 5.22 & 1.49 & \\
\hline \multirow[t]{2}{*}{ Psittaciformes } & 12 & 12 & 5 & 2 & 31 \\
\hline & 20.17 & 6.4 & 3.44 & 0.98 & \\
\hline \multirow[t]{2}{*}{ Galliformes } & 12 & 1 & 2 & 0 & 15 \\
\hline & 9.76 & 3.1 & 1.67 & 0.48 & \\
\hline \multirow[t]{2}{*}{ Anseriformes } & 10 & 8 & 2 & 1 & 21 \\
\hline & 13.67 & 4.33 & 2.33 & 0.67 & \\
\hline \multirow[t]{2}{*}{ Columbiformes } & 10 & 2 & 0 & 0 & 12 \\
\hline & 7.81 & 2.48 & 1.33 & 0.38 & \\
\hline Total & 82 & 26 & 14 & 4 & 126 \\
\hline
\end{tabular}

Chi-square value $=31.7$, degrees of freedom $=12, P=0.003$, estimate $=0.29$.

The greatest number of impacts were recorded in Australasia ( 48 impacts, $38 \%$ of all impacts), followed by Oceanic Islands (26 impacts, 20\%). No impact data were found for South America (Figure 2). Impact data availability is non-randomly distributed, given regional alien species richness (unconditional exact test: chi-square value $=23.8$, degrees of freedom $=5, P<0.001$, estimate $=0.167$ ), a result driven by the larger number of impact reports for Australasia than would be expected by chance (Table 3). Impact magnitudes are randomly distributed across regions (unconditional exact test: chi-square value $=0.208$, degrees of freedom $=5, P=0.98$, estimate $=0.04)($ Suppl. material 3: Table S5). Impact mechanisms are also randomly distributed across regions (chi-square value $=9.318$, degrees of freedom $=15, P=0.812$, estimate $=0.156)$ (Suppl. material 3: Table S6). 
Table 3. Contingency table (unconditional exact test) showing actual and expected numbers of impact reports and regional alien species richness scores. Expected values are displayed in italics.

\begin{tabular}{lccc}
\hline & No. of alien bird species (alien species richness) & No. of impact reports & Total \\
\hline Africa & 50 & 7 & $\mathbf{5 7}$ \\
Asia & 48.48 & 8.52 & $\mathbf{1 3 2}$ \\
& 121 & 11 & $\mathbf{1 4 7}$ \\
Australasia & 112.26 & 19.74 & \\
Europe & 99 & 48 & $\mathbf{1 3 2}$ \\
& 125.02 & 21.98 & $\mathbf{1 7 2}$ \\
North and Central America & 112 & 20 & $\mathbf{2 1 6}$ \\
Oceanic Islands & 112.26 & 19.74 & $\mathbf{1 6}$ \\
& 156 & 25.72 & $\mathbf{8 5 6}$ \\
Total & 146.28 & 26 & \\
\hline
\end{tabular}

Chi-square value $=23.8$, degrees of freedom $=5, P<0.001$, estimate $=0.17$.

The majority of recorded impacts were allocated a 'Low' confidence score (121 impacts, 95\% of all impacts); five impacts were allocated a 'Medium' confidence score and two were allocated a 'High' confidence score. Confidence scores are randomly distributed across impact mechanisms (unconditional exact test: chi-square value $=$ 1.7, degrees of freedom $=6, P=0.86$, estimate $=0.082)($ Suppl. material 3: Table S7). Confidence scores are also randomly distributed across regions (chi-square value $=1.4$, degrees of freedom $=10, P=0.98$, estimate $=0.074)($ Suppl. material 3: Table S8). Confidence scores are non-randomly distributed across impact magnitudes (chi-square value $=8.17$, degrees of freedom $=2, P=0.01$, estimate $=0.206$ ) (Suppl. material 3: Table S9), with higher confidence being placed in impacts of higher magnitude.

\section{Discussion}

As far as we are aware, this study represents the first global assessment of the socio-economic impacts of alien birds. Our literature search identified data on socio-economic impacts for just $14 \%$ of the 415 alien bird species with self-sustaining populations worldwide. This paucity of impact data reflects the findings of other studies on the socio-economic impacts of alien species, including SEICAT assessments undertaken for amphibians (Bacher et al. 2018; Measey et al. 2020) and gastropods (Kesner and Kumschick 2018). Taken together, this suggests that the socio-economic impacts of most alien species are unknown.

There are at least four reasons why we may lack data on the socio-economic impacts of alien birds. First, some species may have, or be perceived to have, socio-economic impacts that are minor and do not cause problems for human beings, and hence do not warrant socio-economic impact research. Research on the environmental impacts of alien species tends to focus on species that have the most damaging environmen- 
tal impacts (Pyšek et al. 2008), and for alien birds, we are likely to lack data on the environmental impacts of many species because their impacts are minor (Evans et al. 2018). If this is also true for alien species socio-economic impact research, the results of this study suggest that the socio-economic impacts of alien birds are generally minor and unlikely to pose a severe threat to human well-being.

Second, the impacts of some species may be going unnoticed because they occur in regions of the world with limited capacity to study their impacts or in remote regions where those impacts are not easily recorded. Consistent with this hypothesis, we find more data on the socio-economic impacts of alien birds in developed regions: 66\% of impacts occur in Australasia, Europe and North America; 14\% occur in Asia and Africa; no impact data were found for South America (Figure 2). Of the $26 \mathrm{im}$ pacts occurring on islands, approximately $70 \%$ relate to developed nations or overseas territories thereof (e.g. Hawaii, New Caledonia, Bermuda, St Helena, Netherlands Antilles). This pattern is also evident for alien bird environmental impact research (Martin-Albarracin et al. 2015; Evans et al. 2018; Evans and Blackburn 2020), alien amphibian impact research (Measey et al. 2020), and for alien species research more generally (Bellard and Jeschke 2015), and suggests we may have much to learn about the impacts of alien birds on human well-being in developing regions. This is of concern as the impacts of alien species can be a major threat to human livelihoods in developing countries, particularly by affecting agricultural production and hence food security (Perrings 2005).

Third, the tendency for impacts to be recorded in developed regions may also reflect the global distribution of alien bird species, which tends to show high species richness in Europe, former European colonies such as the USA, Australia and New Zealand, and economic hotspots such as Singapore, Hong Kong and Taiwan (Dyer et al. 2017b). Nevertheless, Australasia has more impact reports deriving from the region than would be expected by chance given the number of alien bird species established there (the region also has many more impact reports than would be expected if alien species richness is ignored) (Table 3). This suggests that impacts in Australasia may be over-reported, lending support to our previous hypotheses that impacts are less frequently reported in developing regions.

Fourth, research on socio-economic impacts may be biased towards species with existing environmental impacts. Of the 57 alien bird species with reported socio-economic impacts, approximately $80 \%$ (45) also have reported environmental impacts; of the 358 species that are DD for socio-economic impacts, approximately $80 \%$ (284) are also DD for environmental impacts (Table 1). This implies that in general, alien bird species with environmental impacts have socio-economic impacts. Indeed, across taxa (and regions), the environmental and socio-economic impacts of alien species are highly correlated (Vilà et al. 2010). If this is the case, predicting which species are likely to have socio-economic impacts may be informed by determining whether they have environmental impacts. However, this result may also arise because alien bird species with damaging environmental impacts are noticed and studied, and these assessments also include a review of their socio-economic impacts. Indeed, several alien species impact 
scoring schemes require consideration of both the environmental and socio-economic impacts (e.g. the Generic Impact Scoring System (GISS) (Nentwig et al. 2016), Harmonia+ (D'hondt et al. 2014) and the UK risk assessment scheme for all non-native species (Baker et al. 2008)). If this is true, the impacts of alien bird species that have socio-economic impacts, but do not have environmental impacts, may be going unnoticed (the fact that there are more data on environmental than socio-economic impacts suggests this direction of causation, rather than vice versa). This may be why the same five orders that account for $90 \%$ of species with environmental impact data (Evans et al. 2016) also account for almost $90 \%$ of species with socio-economic impact data.

The socio-economic impacts of alien birds are generally minor (Figure 2), with all but two of the 128 recorded impacts being either MC (i.e. no deleterious impact was identified) or MN (i.e. whilst the impacts of an alien bird may make it difficult for humans to participate in an activity, they did not lead to a decline in the size of an activity). Two species were found to have MO impacts. First, frugivory by the Eurasian blackbird contributed to the decline of the small-fruit growing industry across Tasmania in the 1800s (Guiler 1989). Second, a collision with a flock of common starlings at Boston Airport in 1960 resulted in an aeroplane crash that killed 62 people (Dolbeer 2013). Although this event is unlikely to have caused a reduction in aviation activities and airline passenger numbers in the USA, under SEICAT, any impact resulting in a human fatality automatically qualifies as an MO impact (see Suppl. material 1: Table S1).

The prevalence of $\mathbf{M C}$ and $\mathbf{M N}$ impacts may support our hypothesis that we lack impact data for many alien bird species because their socio-economic impacts are negligible and do not attract research. However, a 'Low' confidence score was assigned to $95 \%$ of SEICAT alien bird impact assessments because, whilst adequate data were available to ascertain that an alien bird was exerting an impact, there were inadequate data to determine how severely this impact affected human well-being (in particular, to distinguish between an $\mathbf{M N}$ impact (where an alien bird makes an activity difficult) and an MO impact (where it causes a decline in the population participating in an activity)). This may be because whilst these studies identified socio-economic impacts, they did not go on to quantify how they affected the scale of the impacted activities. For example, by eating rice grown for duck feed, the Eurasian tree sparrow (Passer montanus) causes economic losses for duck farmers in the Philippines (Libay et al. 1983). Whilst empirical evidence is available to confidently determine that the sparrows cause economic losses (an MN impact under SEICAT), there is inadequate information to determine whether these impacts have resulted in some people abandoning duck farming activities in the region (an MO impact). Consequently, rice predation by sparrows on duck farming in the Philippines is classified as an MN impact with a 'Low' confidence score. SEICAT is a new framework that requires specific data on the level of impact on human activities, which as yet is unavailable for many alien bird impacts. The adoption of SEICAT may therefore foster a broader approach to future alien species socio-economic impact assessments, which will not only describe impacts, but also consider their wider implications for human well-being. We recommend that future studies on the socio-economic impacts of alien species go beyond the identification 
of impacts, by attempting to quantify how these impacts reduce the scale of affected activities. We also recommend that these assessments are not based on anecdotal evidence, as this would most likely improve the level of confidence allocated to future SEICAT assessments.

From the data that are currently available, the most severe impacts on human wellbeing caused by alien birds are associated with aviation safety (an air strike with a flock of common starlings having caused the deadliest bird-induced plane crash in history (Dolbeer 2013)). Collisions with birds (both native and alien) have resulted in the loss of at least 190 lives and 52 aircraft, and cost the global aviation industry approximately US\$ 1.2 billion/year (€ 1.1 billion/year) in damage and delays (Allan 2000). Three alien bird species continue to be adjudged to pose a significant threat to aviation safety: the Canada goose, rose-ringed parakeet and common starling. Of these species, the Canada goose may represent the most serious threat, due to its large body size, flocking nature and attraction to managed grasslands as found at airports (Bradbeer et al. 2017). It is present in large numbers at Heathrow Airport in the UK, where it has caused at least one serious safety incident: in 1998, a Boeing 767 collided with a flock of Canada geese when coming in to land, damaging the nose, wing and left engine of the plane (Civil Aviation Authority, no date). In its native range in North America, air strikes with Canada geese have caused several serious safety incidents, including a crash in which 24 people died (Bradbeer et al. 2017) and an emergency landing on the Hudson River in New York City (Marra et al. 2009; Dolbeer 2011). The rose-ringed parakeet is also present at Heathrow Airport: between 2005 and 2006, three of the 98 reported airstrikes at the airport involved this species (Avery and Shiels 2017). The common starling poses a growing threat to aviation safety across the USA: between 1990 and 2001, there were 852 reported strikes that involved common starlings, and over that time-period the annual strike rate more than doubled. Together with airstrikes involving native blackbird species, these incidents cost approximately US\$1.6 million (€ 1.4 million), although damage to aircraft was only reported in approximately $6 \%$ of strikes (Barras et al. 2003). Alien birds may continue to contribute disproportionately to bird strikes because of their greater tendency to be found in anthropogenic environments, in both their native and alien ranges (Cardador and Blackburn 2019).

Impacts on agriculture account for approximately two-thirds of all recorded impacts (Figure 2). Nearly $40 \%$ of these impacts occur in Australasia. This may be for a number of reasons: Australia and New Zealand are developed countries with the capacity to undertake and publish research on the impacts of alien species; both countries have been subject to many deliberate alien bird introductions (McDowall 1994; Dyer et al. 2017a), including several frugivorous species (e.g. common myna, common starling, Eurasian blackbird, house sparrow); and both countries have economically important fruit-growing industries that have been affected by pest birds (Tracey et al. 2007). Damage to the fruit-growing industry in Australia is estimated to cost AU $\$ 300$ million (€ 180 million) annually. Together, these reasons may explain why there are many more impact reports than would be expected by chance in Australasia, given its alien species richness score (Table 3). However, this impact is not caused by alien birds alone, as more than 60 bird species (the majority being native) are known agricultural 
pests in Australia (Tracey et al. 2007). While these agricultural impacts may be financially costly, there is little evidence to indicate that they reduce the scale of agricultural activities in Australia (or have done recently, at least; Guiler 1989). Thus the large financial losses that may be incurred only rate as a Minor (MN) impact under SEICAT.

There are few data on the spread of diseases by alien birds and the subsequent socio-economic impacts (Figure 2) or environmental impacts (Evans et al. 2016). This may be because disease assessments are complex: it is often difficult to confirm whether a specific species has transmitted a disease (see Tompkins and Jakob-Hoff 2011), although exotic parakeets kept as pets in the UK were associated with disease scares that may have contributed to their unplanned introduction (Heald et al. 2019). Almost half of the 26 impacts on public facilities are generated by parrot species (Table 2). This is likely to be because parrots often possess high levels of urban tolerance (Maklakov et al. 2011), facilitating their establishment in urban areas (e.g. Diamond and Ross (2019)). This may explain the general prevalence of parrot species in our dataset (Figure 1). Examples include the monk parakeet (see Introduction); the sulphur-crested cockatoo (Cacatua galerita) and Alexandrine parakeet (Psittacula eupatria) which damage ornamental trees in public parks in Australia and Iran, respectively (Khaleghizadeh 2004; Department of Environment and Conservation 2009); the rose-ringed parakeet which disturbs residents and tourists on Hawaii with its loud calls (Shiels and Kalodimos 2019); and the long-billed corella (Cacatua tenuirostris) and little corella (Cacatua sanguinea) which damage grass sports pitches in Western Australia (Department of Environment and Conservation 2009). The prevalence of waterfowl species with impacts on public facilities (Table 2) is primarily caused by the Canada goose, which has a rapidly expanding population across northwest Europe (Banks et al. 2008), where it fouls public spaces such as parks, sports pitches and swimming ponds with droppings (see van Haam et al. 2013).

We have more confidence in the accuracy of SEICAT assessments where the impacts on human well-being are more severe (Suppl. material 3: Table S9). This may be because one of the two 'more severe' impacts in our dataset resulted in human fatalities which meant it automatically qualified as an $\mathbf{M O}$ impact, and was thus assigned a 'High' confidence score. As there are only two 'more severe' impacts in our dataset, we do not place much emphasis on this result.

\section{Conclusions}

This study represents the first large-scale application of the SEICAT protocol, and the first global assessment of the socio-economic impacts of alien birds. It demonstrates that SEICAT can be used effectively to quantify and categorise the impacts of alien species on human well-being. The most significant problem encountered during this assessment was a lack of impact data: we only know about the socio-economic impacts of a small proportion of the alien birds with self-sustaining populations worldwide. This study may therefore help to focus research regarding the impacts of alien birds on human well-being, particularly in developing regions of the world, where impact data 
are scarce. Birds are well-studied in comparison to many other taxonomic groups, and thus the problem of data paucity may extend to SEICAT assessments for other groups yet to be assessed, such as invertebrates. Nevertheless, completion of these assessments would reveal the global taxonomic distribution of impact data availability (see Evans and Blackburn 2020), and hence inform future socio-economic impact research.

SEICAT is a new framework, requiring data on the way in which alien species affect human well-being, as measured by changes to human activities: even where we do have data describing an alien bird impact, data on how profoundly this impact affects people's activities are often unavailable. As a result, the confidence assigned to most SEICAT classifications is 'Low'. The adoption of SEICAT may encourage a more holistic approach to future socio-economic impact assessments which not only describe impacts, but also consider their wider implications for human well-being.

\section{Acknowledgements}

T.E. is supported by the Alexander von Humboldt Foundation. A.F.P. and S.B. are supported by the Swiss National Science Foundation (grant number 31003A_179491); S.B. and J.M.J. are supported by the Belmont Forum - BiodivERsA International joint call project InvasiBES (PCI2018-092939, BMBF grant 01LC1803A); and S.B. by the Swiss National Science Foundation (grant number 31BD30_184114).

This paper was presented at a workshop on 'Frameworks used in Invasion Science' hosted by the DSI-NRF Centre of Excellence for Invasion Biology in Stellenbosch, South Africa, 11-13 November 2019, that was supported by the National Research Foundation of South Africa and Stellenbosch University.

\section{References}

Allan JR (2000) The costs of bird strikes and bird strike prevention. Human conflicts with wildlife: economic considerations. 18: 147-153. http://digitalcommons.unl.edu/nwrchumanconflicts/18/

Avery ML, Shiels AB (2018) Monk and rose-ringed parakeets. In: Pitt WC, Beasley JC, Witmer GW (Eds) Ecology and Management of Terrestrial Vertebrate Invasive Species in the United States. CRC Press, Boca Raton, 403 pp. https://doi.org/10.1201/9781315157078

Avery ML, Greiner EC, Lindsay JR, Newman JR, Pruett-Jones S (2002) Monk parakeet management at electric utility facilities in south Florida. USDA National Wildlife Research Center - Staff Publications. Paper 458: 140-145. https://doi.org/10.5070/V420110236

Bacher S, Blackburn TM, Essl F, Genovesi P, Heikkilä J, Jeschke JM, Jones G, Keller R, Kenis M, Kueffer CM, Angeliki F, Nentwig W, Pergl J, Pyšek P, Rabitsch W, Richardson DM, Roy HE, Saul WC, Scalera R, Vilà M, Wilson JRU, Kumschick S (2018) Socio-economic impact classification of alien taxa (SEICAT). Methods in Ecology and Evolution 9(1): 159-168. https://doi.org/10.1111/2041-210X.12844 
Baker RH, Harvey KJ, French K (2008) The UK risk assessment scheme for all non-native species. In: Rabitsch W, Essl F, Klingenstein F (Eds) Biological invasions - from ecology to conservation. NeoBiota 7: 46-57. https://doi.org/10.1111/j.1523-1739.2006.00615.x

Banks AN, Wright LJ, Maclean IMD, Hann C, Rehfisch MM (2008) Review of the status of introduced non-native waterbird species in the area of the African-Eurasian Waterbird Agreement: 2007 Update. BTO Research Report No. 489. British Trust for Ornithology. http://139.222.132.34/sites/default/files/u196/downloads/rr489.pdf

Barras SC, Wright SE, Seamans TW (2003) Blackbird and starling strikes to civil aircraft in the United States, 1990-2001. USDA National Wildlife Research Center - Staff Publications. 200: 91-96.

Bellard C, Jeschke JM (2015) A spatial mismatch between invader impacts and research publications. Conservation Biology 30(1): 230-232. https://doi.org/10.1111/cobi.12611

Blackburn TM, Essl F, Evans T, Hulme PE, Jeschke JM, Kühn I, Kumschick S, Marková Z, Mrugała A, Nentwig W, Pergl J, Pyšek P, Rabitsch W, Ricciardi A, Richardson DM, Sendek A, Vilà M, Wilson JRU, Winter M, Genovesi P, Bacher S (2014) A unified classification of alien species based on the magnitude of their environmental impacts. PLoS Biology 12(5): e1001850. https://doi.org/10.1371/journal.pbio.1001850

Bradbeer DR, Rosenquist C, Christensen TK, Fox AD (2017) Crowded skies: conflicts between expanding goose populations and aviation safety. Ambio 46(s2): S290-S300. https://doi. org/10.1007/s13280-017-0901-2

Canavan S, Kumschick S, Le Roux JJ, Richardson DM, Wilson JRU (2019) Does origin determine environmental impacts? Not for bamboos. Plants, People, Planet 1(2): 119-128. https://doi.org/10.1002/ppp3.5

Cardador L, Blackburn M (2019) Human-habitat associations in the native distributions of alien bird species. Journal of Applied Ecology 56: 1189-1199. https://doi.org/10.1111/13652664.13351

Campbell S, Roberts EJ, Craemer R, Pacioni C, Rollins L, Woolnough AP (2016) Assessing the economic benefits of starling detection and control to Western Australia. Australasian Journal of Environmental Management 23(1): 81-99. https://doi.org/10.1080/1448656 3.2015.1028486

Civil Aviation Authority (no date) Large flocking birds: an international conflict between conservation and air safety. Safety Regulation Group, Civil Aviation Authority.

Coro G, Vilas LG, Magliozzi C, Ellenbroek A, Scarponi P, Pagano P (2018) Forecasting the ongoing invasion of Lagocephalus sceleratus in the Mediterranean Sea. Ecological Modelling 371: 37-49. https://doi.org/10.1016/j.ecolmodel.2018.01.007

D'hondt B, Vanderhoeven S, Roelandt S, Mayer F, Versteirt V, Ducheyne E, San Martin G, Grégoire J-C, Stiers I, Quoilin S, Branquart E (2014) Harmonia $^{+}$and Pandora ${ }^{+}$: risk screening tools for potentially invasive organisms. Belgian Biodiversity Platform, Brussels, 63 pp. https://doi.org/10.1007/s10530-015-0843-1

Department of Environment and Conservation (2009) Pest notes: corellas and other flocking cockatoos. Government of Western Australia. https://walga.asn.au/getattachment/Policy-Adviceand-Advocacy/Environment/Pest-Birds/Environment/Pest-Birds-Portal/Information-andResources/DPaW_Pest-Notes_Corellas-and-other-flocking-cockatoos.pdf.aspx?lang=en-AU 
Diamond JM, Ross MS (2019) Exotic parrots breeding in urban tree cavities: nesting requirements, geographic distribution, and potential impacts on cavity nesting birds in southeast Florida. Avian Research 10: 1-10. https://doi.org/10.1186/s40657-019-0176-3

Dolbeer RA (2011) Increasing trend of damaging bird strikes with aircraft outside the airport boundary: implications for mitigation measures. Human-Wildlife Interactions 5(2): 235-248.

Dolbeer RA (2013) The history of wildlife strikes and management at airports. In: DeVault TL, Blackwell BF, Belant JL (Eds) Wildlife in Airport Environments: Preventing AnimalAircraft Collisions Through Science-Based Management. John Hopkins University Press, Baltimore, 200 pp.

Dyer EE, Redding DW, Blackburn TM (2017a) The global avian invasions atlas, a database of alien bird distributions worldwide. Scientific Data 4: 170041. https://doi.org/10.1038/ sdata.2017.41

Dyer EE, Cassey P, Redding DW, Collen B, Franks V, Gaston KJ, Jones KE, Kark S, Orme CDL, Blackburn TM (2017b) The global distribution and drivers of alien bird species richness. PLoS Biology 15(1): e2000942. https://doi.org/10.1371/journal.pbio.2000942

Evans T, Blackburn TM (2020) Global variation in the availability of data on the environmental impacts of alien birds. Biological Invasions 22: 1027-1036. https://doi.org/10.1007/ s10530-019-02153-z

Evans T, Kumschick S, Blackburn TM (2016) Application of the Environmental Impact Classification for Alien Taxa (EICAT) to a global assessment of alien bird impacts. Diversity and Distributions 22: 919-931. https://doi.org/10.1111/ddi.12464

Evans T, Kumschick S, Dyer E, Blackburn T (2014) Comparing determinants of alien bird impacts across two continents: implications for risk assessment and management. Ecology and Evolution 4(14): 2957-2967. https://doi.org/10.1002/ece3.1144

Evans T, Pigot A, Kumschick S, Şekercioğlu ÇH, Blackburn TM (2018) Determinants of data deficiency in the impacts of alien bird species. Ecography 41: 1401-1410. https://doi. org/10.1111/ecog.03232

Fitzwater WD (1973) Madam Saga - an approach to an animal damage problem. Bird Control Seminars Proceedings. 99: 47-52. https://digitalcommons.unl.edu/icwdmbirdcontrol/99/?utm_ source=digitalcommons.unl.edu\%2Ficwdmbirdcontrol\%2F99\&utm_medium=PDF\&utm_ campaign=PDFCoverPages

Guiler ER (1989) The Tasmanian blackbird eradication programme, 1941-47. Papers \& Proceedings of the Royal Society of Tasmania 123: 55-61. https://doi.org/10.26749/rstpp.123.55

van Haam C, Genovesi P, Scalera R (2013) Invasive alien species: the urban dimension. Case studies on strengthening local action in Europe. Brussels, Belgium: IUCN European Union Representative Office, 103 pp.

Heald OJN, Fraticelli C, Cox SE, Stevens MCA, Faulkner SC, Blackburn TM, Le Comber SC (2019) Understanding the origins of the ring-necked parakeet in the UK. Journal of Zoology. https://doi.org/10.1111/jzo.12753

IUCN (2020) Guidelines for using the IUCN Environmental Impact Classification for Alien Taxa (EICAT) Categories and Criteria. First Edition. Gland, Switzerland and Cambridge, UK. doi: 10.2305/IUCN.CH.2020.05.en 
Johnson AW, Millie WR, Moffett G (1970) Notes on the birds of Easter Island. Ibis 112(4): 532-538. https://doi.org/10.1111/j.1474-919X.1970.tb00823.x

Josseran L, Paquet C, Zehgnoun A, Caillere N, Le Tertre A, Solet J-L, Ledrans M (2006) Chikungunya disease outbreak, Reunion Island. Emerging Infectious Diseases 12(12): 1994-1995. https://doi.org/10.3201/eid1212.060710

Kesner D, Kumschick S (2018) Gastropods alien to South Africa cause severe environmental harm in their global alien ranges across habitats. Ecology and Evolution 8(16): 8273-8285. https://doi.org/10.1002/ece3.4385

Khaleghizadeh A (2004) On the diet and population of the Alexandrine parakeet, Psittacula eupatria, in the urban environment of Tehran, Iran. Zoology in the Middle East 32: 27-32. https://doi.org/10.1080/09397140.2004.10638040

Kumschick S, Nentwig W (2010) Some alien birds have as severe an impact as the most effectual alien mammals in Europe. Biological Conservation 143: 2757-2762. https://doi. org/10.1016/j.biocon.2010.07.023

Kumschick S, Bacher S, Blackburn TM (2013) What determines the impact of alien birds and mammals in Europe? Biological Invasions 15(4): 785-797. https://doi.org/10.1007/ s10530-012-0326-6

Libay JL, Fiedler LA, Bruggers RL (1983) Feed losses to European tree sparrows (Passer montanus) at duck farms in the Philippines. Bird Control Seminars Proceedings. 279: 135-142. https://digitalcommons.unl.edu/icwdmbirdcontrol/279/?utm_source=digitalcommons. unl.edu\%2 Ficwdmbirdcontrol\%2F $79 \&$ ut m_medium = PDF \&utm_ campaign $=$ PDFCoverPages

Maklakov AA, Immler S, Gonzalez-Voyer A, Rönn J, Kolm N (2011) Brains and the city: bigbrained passerine birds succeed in urban environments. Biology Letters 7(5): 730-732. https://doi.org/10.1098/rsbl.2011.0341

Marra PP, Dove CJ, Dolbeer R, Dahlan NF, Heacker M, Whatton JF, Diggs NE, France C, Henkes GA (2009) Migratory Canada geese cause crash of US Airways Flight 1549. Frontiers in Ecology and the Environment 7(6): 297-301. https://doi.org/10.1890/090066

Martin-Albarracin VL, Amico GC, Simberloff D, Nuñez MA (2015) Impact of non-native birds on native ecosystems: a global analysis. PloS ONE 10(11): e0143070. https://doi. org/10.1371/journal.pone.0143070

McDowall M (1994) Gamekeepers for a Nation: the Story of New Zealand's Acclimatisation Societies, 1861-1990. Canterbury University Press, Christchurch.

Measey J, Wagener C, Mohanty NP, Baxter-Gilbert J, Pienaar EF (2020) The cost and complexity of assessing impact. In: Wilson JR, Bacher S, Daehler CC, Groom QJ, Kumschick S, Lockwood JL, Robinson TB, Zengeya TA, Richardson DM (Eds) Frameworks used in Invasion Science. NeoBiota 62: 279-299. https://doi.org/10.3897/neobiota.62.52261

Naylor R (1996) Invasions in agriculture: assessing the cost of the golden apple snail in Asia. Ambio 25(7): 443-448. http://www.jstor.org/stable/4314515

Nentwig W, Kühnel E, Bacher S (2010) A generic impact-scoring system applied to alien mammals in Europe. Conservation Biology 24(1): 302-311. https://doi.org/10.1111/j.15231739.2009.01289.x 
Nentwig W, Bacher S, Pyšek P, Vilà M, Kumschick S (2016) The generic impact scoring system (GISS): a standardized tool to quantify the impacts of alien species. Environmental Monitoring and Assessment 188: 1-315. https://doi.org/10.1007/s10661-016-5321-4

Perrings C (2005) The socioeconomic links between invasive alien species and poverty. Report to the Global Invasive Species Program. https://www.gisp.org/publications/reports/ Perrings.pdf

Pimentel D, McNair S, Janecka J, Wightman J, Simmonds C, O’Connell C, Wong E, Russel L, Zern J, Aquino T, Tsomondo T (2001) Economic and environmental threats of alien plant, animal, and microbe invasions. Agriculture, Ecosystems and Environment 84(1): 1-20. https://doi.org/10.1016/S0167-8809(00)00178-X

Probert AF, Volery L, Kumschick S, Vimercati G, Bacher S (2020) Understanding uncertainty in the Impact Classification for Alien Taxa (ICAT) assessments. In: Wilson JR, Bacher S, Daehler CC, Groom QJ, Kumschick S, Lockwood JL, Robinson TB, Zengeya TA, Richardson DM (Eds) Frameworks used in Invasion Science. NeoBiota 62: 387-405. https:// doi.org/10.3897/neobiota.62.52010

Pyšek P, Richardson DM, Pergl J, Jarošík V, Sixtová Z, Weber E (2008) Geographical and taxonomic biases in invasion ecology. Trends in Ecology and Evolution 23(5): 237-244. https://doi.org/10.1016/j.tree.2008.02.002

R Core Team (2019) R: A language and environment for statistical computing. R Foundation for Statistical Computing, Vienna. https://www.R-project.org/

Shiels AB, Kalodimos NP (2019) Biology and impacts of Pacific island invasive species. 15. Psittacula krameri, the rose-ringed parakeet (Psittaciformes: Psittacidae). Pacific Science 73(4): 421-449. https://doi.org/10.2984/73.4.1

Shirley SM, Kark S (2009) The role of species traits and taxonomic patterns in alien bird impacts. Global Ecology and Biogeography 18(4): 450-459. https://doi.org/10.1111/j.14668238.2009.00452.x

Tompkins DM, Jakob-Hoff R (2011) Native bird declines: don't ignore disease. Letter to the Editor. Biological Conservation 144: 668-669. https://doi.org/10.1016/j.biocon.2010.09.027

Tracey J, Saunders G (2003) Bird damage to the wine grape industry. Vertebrate Pest Research Unit, NSW Agriculture. Report to the Bureau of Rural Sciences, Department of Agriculture, Fisheries and Forestry: 1-192.

Tracey J, Bomford M, Hart Q, Saunders G, Sinclair R (2007) Managing bird damage to fruit and other horticultural crops. Bureau of Rural Sciences, Canberra. Australian Government. 
Vilà M, Basnou C, Pyšek P, Josefsson M, Genovesi P, Gollasch S, Nentwig W, Olenin S, Roques A, Roy D, Hulme PE, DAISIE partners (2010) How well do we understand the impacts of alien species on ecosystem services? A pan-European, cross-taxa assessment. Frontiers in Ecology and the Environment 8(3): 135-144. https://doi.org/10.1890/080083

Zhong H, Song M (2019) A fast exact functional test for directional association and cancer biology applications. IEEE/ACM Transactions on Computational Biology and Bioinformatics 16(3): 818-826. https://doi.org/10.1109/TCBB.2018.2809743

\section{Supplementary material I}

\section{Appendix A}

Authors: Thomas Evans, Tim M. Blackburn, Jonathan M. Jeschke, Anna F. Probert, Sven Bacher

Data type: (measurement/occurrence/multimedia/etc.)

Explanation note: Alien bird SEICAT assessment: literature review protocol.

Copyright notice: This dataset is made available under the Open Database License (http://opendatacommons.org/licenses/odbl/1.0/). The Open Database License $(\mathrm{ODbL})$ is a license agreement intended to allow users to freely share, modify, and use this Dataset while maintaining this same freedom for others, provided that the original source and author(s) are credited.

Link: https://doi.org/10.3897/neobiota.62.51150.suppl1

\section{Supplementary material 2}

\section{Appendix B}

Authors: Thomas Evans, Tim M. Blackburn, Jonathan M. Jeschke, Anna F. Probert, Sven Bacher

Data type: (measurement/occurrence/multimedia/etc.)

Explanation note: Alien bird SEICAT assessment (species summary).

Copyright notice: This dataset is made available under the Open Database License (http://opendatacommons.org/licenses/odbl/1.0/). The Open Database License $(\mathrm{ODbL})$ is a license agreement intended to allow users to freely share, modify, and use this Dataset while maintaining this same freedom for others, provided that the original source and author(s) are credited.

Link: https://doi.org/10.3897/neobiota.62.51150.suppl2 


\section{Supplementary material 3}

\section{Nine additional tables}

Authors: Thomas Evans, Tim M. Blackburn, Jonathan M. Jeschke, Anna F. Probert, Sven Bacher

Data type: Tables

Explanation note: Table S1. Impact descriptions used to guide the SEICAT assessment process (from Bacher et al. 2018). Table S2. Contingency table (unconditional exact test) showing actual and expected numbers of alien bird species for each order, with and without recorded impacts. Table S3. Contingency table (unconditional exact test) showing actual and expected numbers of impact allocations to less severe $(\mathrm{MC} \& \mathrm{MN})$ and more severe $(\mathrm{MO})$ impact categories for each alien bird order. Table S4. Contingency table (unconditional exact test) showing actual and expected numbers of impact allocations to less severe (MC \& MN) and more severe (MO) impact categories for each impact mechanism. Table S5. Contingency table (unconditional exact test) showing actual and expected numbers of impact allocations by region, to less severe ( $\mathrm{MC} \& \mathrm{MN}$ ) and more severe (MO) impact categories. Table S6. Contingency table (unconditional exact test) showing actual and expected numbers of impact allocations by region, to each impact mechanism. Table S7. Contingency table (unconditional exact test) showing actual and expected numbers of impact allocations by confidence score, to less severe (MC \& MN) and more severe (MO) impact categories. Table S8. Contingency table (unconditional exact test) showing actual and expected numbers of impact allocations by confidence score, to each region. Table S9. Contingency table (unconditional exact test) showing actual and expected numbers of impact allocations by confidence score, to less severe (MC \& MN) and more severe (MO) impact categories.

Copyright notice: This dataset is made available under the Open Database License (http://opendatacommons.org/licenses/odbl/1.0/). The Open Database License $(\mathrm{ODbL})$ is a license agreement intended to allow users to freely share, modify, and use this Dataset while maintaining this same freedom for others, provided that the original source and author(s) are credited.

Link: https://doi.org/10.3897/neobiota.62.51150.suppl3 